\title{
Water-triggered spontaneous surface patterning in thin films of mexylaminotriazine molecular glasses
}

\author{
Elizabeth Melito, ${ }^{a}$ Audrey Laventure, ${ }^{b}$ Gabriela Aldea-Nunzi, ${ }^{a}$ Christian Pellerin, ${ }^{b}$ Erwin Buncel, ${ }^{a}$ Olivier \\ Lebel, ${ }^{c}$ and Jean-Michel Nunzi ${ }^{\star, a}$
}

\author{
Received (in XXX, XXX) Xth XXXXXXXXX 200X, Accepted Xth XXXXXXXXX 200X \\ First published on the web $X$ th $X X X X X X X X X 200 X$ \\ DOI: 10.1039/b00000000x
}

Surface patterning that occurs spontaneously during the formation of a thin film is a powerful tool for controlling film morphology at the nanoscale level because it avoids the need for further processing. However, one must first learn under which conditions these patterning phenomena occur or not, and how to achieve control over the surface morphologies that are generated. Mexylaminotriazine-based molecular glasses are small molecules that can readily form amorphous thin films. It was discovered that this class of materials can either form smooth films, or films exhibiting either dome or pore patterns. Depending on the conditions, these patterns can be selectively obtained during film deposition by spin-coating. It was determined that this behavior is controlled by the presence of water or, more generally, of a solvent in which the compounds are insoluble, and that the relative amount and volatility of this poor solvent determines which type of surface relief is obtained. Moreover, AFM and FT-IR spectroscopy have revealed that the thin films are amorphous independently of surface morphology, and no difference was observed at the molecular or supramolecular level. These findings make this class of materials and this patterning approach in general extremely appealing for the control of surface morphology with organic nanostructures.

\section{Introduction}

The ability to generate polycrystalline or amorphous thin films lies at the very foundation of several applications, including electronic and opto-electronic devices. ${ }^{1}$ More specifically, the morphology of these micrometers or even nanometers thick films is of crucial importance in determining several of the material properties, including their optical and electronic properties, surface area, stability, and sensitivity to external stimuli. ${ }^{2}$ It also affects their interactions with the environment, for instance their permeability, affinity to various liquids, crystal nucleation and adhesion. ${ }^{3}$ Despite the progress that has been made in developing organic thin film materials for electronic applications, fundamental questions regarding the thin film geometry still remain. ${ }^{4}$ In particular, the amorphous films often used in devices are very susceptible to extreme morphological instabilities. ${ }^{5}$ One of the keys to avoid these undesirable surface irregularities is to control the interactions at the free surface and at the film/substrate interface. While several strategies have been developed for surface patterning, including embossing, etching and lithography, ${ }^{6}$ they often bring the disadvantage of requiring post-processing treatments, which add to the overall cost and time of fabrication. On the other hand, surface patterning that occurs naturally during the film preparation process, such as precipitation or dewetting and related phenomena, can induce the apparition of surface patterns in thin films in a spontaneous fashion. ${ }^{7,8}$ Spontaneous surface patterning is a result of instabilities in the film caused by the difference of surface energy between the film and the substrate, or phase segregation in the case of spinodal dewetting of multicomponent systems. ${ }^{9}$

The formation of surface patterns in an organic film is generally undesirable and implicated as one of the main mechanisms in a device failure. ${ }^{10}$ In contrast, when used in conjunction with materials designed to exhibit specific functionalities, surface patterning can prove a promising tool that can enhance performance for a wide range of practical applications, ${ }^{11}$ including tandem polymer OLEDs, bulk heterojunction photovoltaic cells, ${ }^{12}$ sub-micrometer channels in field effect transistors, ${ }^{13}$ resist patterning of PMMA or PEDOT leading to the formation of mesoscale patterns for radio frequency ID tags, ${ }^{14}$ templated biological micro-electromechanical systems, ${ }^{15}$ and templated plasmonic structures. ${ }^{16}$ Spontaneous surface patterning occurring during thin film formation thus constitutes an appealing method for patterning surfaces, and it is crucial to understand how one can control it or suppress it altogether when it is undesirable. While such behavior has been documented in several instances like molecular films on insulators, ${ }^{17}$ block copolymers, polymer blends, and metal nanoparticles, ${ }^{18}$ only a few cases of surface patterning occurring spontaneously during formation of small molecules thin films have been reported to date, ${ }^{19}$ and even fewer involving single-component systems. ${ }^{20-24}$

In this paper, we studied the film growth and surface patterning of mexylaminotriazine glasses. We have shown previously that these derivatives can readily form glassy phases with high resistance to crystallization. ${ }^{25}$ Hydrogen bonding between triazine units has been revealed to exist in the glassy state, the resulting supramolecular aggregates frustrating the molecular reorganization required for 
crystallization. ${ }^{26-27}$ It has been demonstrated that molecular structure plays a crucial role in determining the glass-forming ability and glass transition temperature. ${ }^{28-30}$ In particular, the consistency of the mexylaminotriazine core in promoting glass formation enables the design and synthesis of molecular

In this work, we found that some nonpolar mexylaminotriazine glasses exhibit surface patterns when deposited by spin-coating from certain solvents, while under other conditions, smooth, uniform films are obtained. While not true dewetting, this behavior, called "pseudo-partial wetting" ${ }^{32}$ (and further referred to as surface patterning for simplicity), can be readily controlled by the amount of poor solvent (in this case, water) present in solution. Indeed, the patterning of a water-soluble mexylaminotriazine glass can also be triggered by the presence of a small amount of nonpolar solvent in solution, rather than water. Atomic force microscopy (AFM) and scanning electron microscopy (SEM) revealed the formation of various types of surface morphologies for patterned films, which can be controlled by the solvent used. Despite the radically different surface topologies observed between smooth and patterned films, aggregation at the molecular level is essentially unaffected, as evidenced by Fourier transform infrared (FT-IR) spectroscopy. Our work shows that water-triggered patterning constitutes a general, simple, elegant and appealing way to control surface topology, and thereby surface properties, in thin films of moderately hydrophobic mexylaminotriazine glasses.

\section{Experimental Section}

\section{General}

Compounds 1-3 and 2-mexylamino-4-methylamino-6-[3(bromomethyl)phenylamino]-1,3,5-triazine were synthesized and characterized according to literature procedures. ${ }^{25,29} \mathrm{~N}$ Methylimidazole was purchased from Oakwood Chemicals. Solvents were purchased from Caledon Laboratories or Fisher Scientific and used without further purification unless otherwise indicated. Differential scanning calorimetry (DSC) measurements were conducted on compound 4 using a Q1000 calorimeter (TA Instruments) calibrated with indium, under a $10{ }^{\circ} \mathrm{C} / \mathrm{min}$ heating rate. The $\mathrm{T}_{\mathrm{g}}$ value was determined from the second heating cycle. The infrared spectrum of compound 4 was recorded with a resolution of $4 \mathrm{~cm}^{-1}$ on a Tensor 27 FT-IR spectrometer (Bruker Optics) equipped with a liquid nitrogencooled HgCdTe detector and a MIRacle (Pike Technologies) silicon attenuated total reflection (ATR) accessory. A film was directly cast from $\mathrm{CH}_{2} \mathrm{Cl}_{2}$ on the ATR crystal. UV-Visible spectra of films spin-coated on $\mathrm{BaF}_{2}$ windows were recorded using a Varian Cary 6000i UV-Vis-NIR spectrometer. Transmission infrared spectra of films spin-coated on $\mathrm{BaF}_{2}$ windows were measured with a resolution of $4 \mathrm{~cm}^{-1}$, using either a Tensor 27 or a Vertex 70 FT-IR spectrometer (Bruker Optics), both equipped with a liquid nitrogen-cooled $\mathrm{HgCdTe}$ detector.

\section{Synthesis of 1-\{[3-(4-mexylamino-6-methylamino-1,3,5- triazin-2-yl)aminophenyl]methyl\}-3-methyl-1H-imidazolium bromide (Glim-Br, 4)}

glasses incorporating moieties with specific functions which would otherwise crystallize, as shown with Disperse Red $1 .^{31}$ Moreover, these materials can be readily deposited from solution from various solvents to generate amorphous thin films in their vitreous phase.

To a solution of 2-mexylamino-4-methylamino-6-[3(bromomethyl)phenylamino]-1,3,5-triazine $\quad(1.00 \mathrm{~g}, \quad 2.42$ $\mathrm{mmol})$ in toluene $(5 \mathrm{~mL})$ in a round-bottomed flask equipped with a magnetic stirrer was added $\mathrm{N}$-methylimidazole $(0.203$ $\mathrm{mL}, 0.209 \mathrm{~g}, 2.54 \mathrm{mmol})$. The flask was equipped with a water-jacketed condenser, then the mixture was refluxed for 4 $\mathrm{h}$, at the end of which a glassy precipitate had formed in the bottom of the flask. The precipitate was crushed, collected by filtration and washed with hot toluene. The product was redissolved in methanol, then thoroughly dried under vacuum to yield $1.24 \mathrm{~g}$ of pure compound 4 (2.42 mmol, 100\%). $\mathrm{T}_{\mathrm{g}} 78$ ${ }^{\circ} \mathrm{C}$; FT-IR (ATR/ $\mathrm{CH}_{2} \mathrm{Cl}_{2}$ ) 3393, 3279, 3144, 3105, 3016, 2951, 2922, 2866, 1612, 1583, 1555, 1516, 1490, 1429, 1404, 1358, 1325, 1302, 1260, 1244, 1181, 1160, 1085, 1035, 997, 976, $887,844,809,746,693,670,621 \mathrm{~cm}^{-1} ;{ }^{1} \mathrm{H}$ NMR $(400 \mathrm{MHz}$, DMSO- $\left.d_{6}, 363 \mathrm{~K}\right) \delta 9.33(\mathrm{~s}, 1 \mathrm{H}), 8.81$ (br s, $\left.1 \mathrm{H}\right), 8.61$ (br s, $1 \mathrm{H}), 7.86(\mathrm{~s}, 1 \mathrm{H}), 7.82\left(\mathrm{~d},{ }^{3} J=7.8 \mathrm{~Hz}, 1 \mathrm{H}\right), 7.76(\mathrm{~s}, 1 \mathrm{H}), 7.71$ (s, 1H), $7.39(\mathrm{~s}, 2 \mathrm{H}), 7.30\left(\mathrm{t},{ }^{3} J=8.1 \mathrm{~Hz}, 1 \mathrm{H}\right), 7.02\left(\mathrm{~d},{ }^{3} J=\right.$ $7.6 \mathrm{~Hz}, 1 \mathrm{H}), 6.74$ (br s, 1H), $6.63(\mathrm{~s}, 1 \mathrm{H}), 5.45$ (s, 2H), 3.91 $(\mathrm{s}, 3 \mathrm{H}), 2.88(\mathrm{~s}, 3 \mathrm{H}), 2.25(\mathrm{~s}, 6 \mathrm{H}) \mathrm{ppm} ;{ }^{13} \mathrm{C} \mathrm{NMR}(100 \mathrm{MHz}$, DMSO- $\left.d_{6}\right) \delta 165.8,164.0,163.6,140.9,139.9,137.1,136.5$, $134.9,128.9,123.8,123.3,122.4,121.0,119.9,119.3,117.7$, 52.0, 35.8, 27.2, $21.1 \mathrm{ppm}$; HRMS (ESI, M+) calcd. for $\mathrm{C}_{23} \mathrm{H}_{27} \mathrm{~N}_{8}$ m/e: 415.2353 , found: 415.2361.

\section{Thin Film Deposition}

Thin films of compounds 1-4 were prepared from $0.02 \mathrm{M}$ solutions in various solvents. Prior to use, partially watermiscible solvents (dichloromethane, ethyl ether, ethyl acetate and 1-butanol) were either dried with $\mathrm{MgSO}_{4}$ powder or saturated with water by shaking with water in an extraction funnel and discarding excess water (ambient humidity was thus considered negligible compared to the water content of these solutions). Substrates were previously rinsed with acetone and submerged in $0.1 \mathrm{M} \mathrm{NaOH}$ solution for about one hour in order to render them hydrophilic, before rinsing with de-ionized water and drying. Hydrophobic substrates were prepared according to a literature procedure. ${ }^{33}$ Spin-coated films were prepared with a Headway Research EC-101 apparatus by depositing $100 \mu \mathrm{L}$ of solution either on glass substrates (subjected to treatments described above) or on a $\mathrm{BaF}_{2}$ window, using the following two-step sequence: rotation speed of $600 \mathrm{rpm}$ for $60 \mathrm{~s}$, immediately followed by an increase of the rotation speed up to $1800 \mathrm{rpm}$ for an additional $60 \mathrm{~s}$.

\section{Microscopy}

An Ambios Q-Scope Atomic Force Microscope was used in the tapping mode with a $40 \mathrm{~N} / \mathrm{m}$ force constant cantilever to record the surface topography and phase images of the thin films.

An environmental FEI Quanta G50 field emission gun scanning electron microscope (SEM) was used at 0.53 Torr 
chamber pressure to image the surface topography of the thin films.

An Axioskop 2 Plus optical microscope (Carl Zeiss) was used to observe the annealing process at $\mathrm{T}_{\mathrm{g}}+15^{\circ} \mathrm{C}$ of films spincoated on glass substrates, using a 10X objective and a THMS 600 hot stage equipped with a TMS 94 temperature controller (Linkam Scientific Instruments).

\section{Results and discussion}

\section{Synthesis and thin film deposition}<smiles>CNc1nc(Nc2cc(C)cc(C)c2)nc(Nc2cc(C)cc(C)c2)n1</smiles>

1<smiles>CNc1nc(Nc2ccc(O)cc2)nc(Nc2cc(C)cc(C)c2)n1</smiles><smiles>CNc1nc(Nc2cc(C)cc(C)c2)nc(NC23CC4CC(CC(C4)C2)C3)n1</smiles>

2<smiles>CNc1nc(Nc2cc(C)cc(C)c2)nc(Nc2cccc(Cn3cc[n+](C)c3)c2)n1</smiles>

Four different glass-forming mexylaminotriazine derivatives were selected for thin film formation, incorporating amino groups of varying polarities: bis(mexylamino) parent compound $\mathbf{1}$, bulky adamantylamino derivative $\mathbf{2}$, more polar 4-hydroxyphenylamino derivative $\mathbf{3}$, and charged imidazolium bromide salt (thereafter referred to as Glim-Br) 4. Compounds 1-3 were synthesized according to literature procedures, ${ }^{25,29}$ while salt 4 was synthesized from the corresponding bromomethyl-substituted glass and $\mathrm{N}$-methylimidazole in refluxing toluene in quantitative yield (Scheme 1).

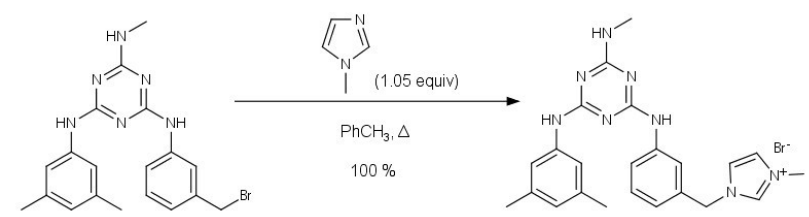

4

Scheme 1 Synthesis of Glim-Br salt 4.

Solutions of compounds 1-4 were prepared in $0.02 \mathrm{M}$ concentration in various solvents, listed in Table 1, and thin films were deposited by spin-coating onto glass substrates. For solvents partially miscible with water, notably dichloromethane, ethyl ether, ethyl acetate and 1-butanol, the solvents were either dried through a pad of $\mathrm{MgSO}_{4}$ or saturated with water, prior to use, to observe the effect of the presence of water on surface morphology.

\section{Surface Morphology}

The morphologies observed for films prepared from the different solvents studied are compiled in Table 1. Smooth (S) and patterned $(\mathrm{Px})$ films could be summarily identified simply by their visual aspect: while smooth films were transparent, patterned films showed a milky appearance. UV-visible spectroscopy was used to confirm these observations. Figure 1 shows that patterned films, such as those of compound $\mathbf{1}$

Table 1 Surface morphology of films of compounds 1-4 cast from $0.02 \mathrm{M}$ solution in various solvents.

$\begin{array}{ccccc}\text { Solvent } & \mathbf{1} & \mathbf{2} & \mathbf{3} & \mathbf{4} \\ \text { Toluene } & & & & \\ \text { Chlorobenzene } & \mathrm{S} & \mathrm{S} & - & - \\ \text { Dichloromethane (dry) } & \mathrm{S} & \mathrm{S} & - & - \\ \text { Dichloromethane (saturated) } & \mathrm{S} & \mathrm{S} & - & - \\ \text { Ethyl ether (dry) } & \mathrm{S} & \mathrm{S} & - & - \\ \text { Ethyl ether (saturated) } & \mathrm{Pd} & \mathrm{P} & \mathrm{S} & - \\ \text { Ethyl acetate (dry) } & \mathrm{S} & \mathrm{S} & \mathrm{Pp} & - \\ \text { Ethyl acetate (saturated) } & \mathrm{Pp} & \mathrm{Pp} & \mathrm{Pp} & - \\ \text { 1-Butanol (dry) } & \mathrm{S} & \mathrm{S} & \mathrm{S} & - \\ \text { 1-Butanol (saturated) } & \mathrm{S} & \mathrm{S} & \mathrm{S} & - \\ \text { THF } & \mathrm{Pp} / \mathrm{i} & \mathrm{Pp} & \mathrm{Pp} & - \\ \text { Acetone } & \mathrm{Pd} & \mathrm{Pd} & \mathrm{Pp} & - \\ \text { Acetonitrile } & \mathrm{Pd} & \mathrm{Pd} & \mathrm{Pi} & - \\ \text { Ethanol } & \mathrm{Pd} & \mathrm{Pd} & \mathrm{Pd} & \mathrm{S} \\ \text { Dioxane } & \mathrm{S} & \mathrm{S} & \mathrm{S} & - \\ \text { DMF } & \mathrm{S} & \mathrm{S} & \mathrm{S} & \mathrm{S} \\ \text { Ethanol/Toluene } 9: 1 & - & - & - & \mathrm{Pd}\end{array}$

S: Smooth film; Pd: Patterned film with domes; Pp: Patterned film with pores; Pi: Patterned film with irregular patterns.

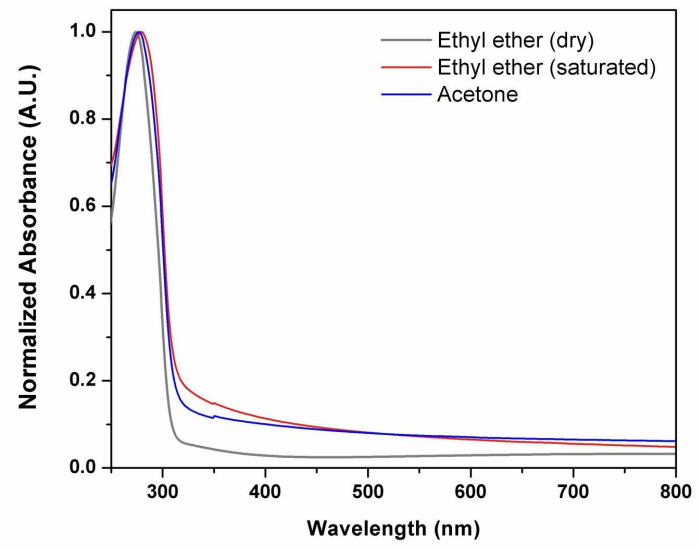

Fig. 1 UV-visible spectra of films of compound 1 cast from dry ethyl ether, water-saturated ethyl ether, and acetone. Absorbance was normalized to the absorption band near $260 \mathrm{~nm}$ for all three films.

prepared from saturated ethyl ether and from acetone, feature a broad scattering band throughout the visible range. This was not observed in smooth films prepared from dry ethyl ether. Spectra of the compounds in solution were essentially 
identical to those of the smooth films, confirming that the observed band in the visible range is due to light scattering and not to actual absorption. This method thus allowed for rapid assessment of the film surface aspect.

It can be seen from Table 1 that, for hydrophobic compounds 1-3, films cast from low-polarity solvents give smooth films, while most highly polar solvents lead to patterned films. Interestingly, the film morphology varies depending on the water content when moderately polar solvents are used, such as ethyl ether or ethyl acetate. Smooth films of compounds 1-3 are obtained when these solvents are dried, while a rough surface is observed when they have been saturated with water, presenting the same behavior as THF, acetone, acetonitrile and ethanol, which are all fully miscible with water. In contrast, dichloromethane is much less miscible with water, and always gave smooth films independent of its water content. It thus seems that water (in which compounds 1-3 are insoluble) is involved in this behavior.

In the cases causing surface patterning mentioned so far, water was always the least volatile solvent. The solvent evaporation sequence presumably has a role to play in this phenomenon, especially when the compound is insoluble in one of the solvents. To explore this idea, films were cast from both dry and water-saturated 1-butanol. 1-Butanol was selected because it possesses both limited miscibility with water and a higher boiling point $\left(118{ }^{\circ} \mathrm{C}\right)$ than water, which ensures that it will evaporate last during thin film deposition.

Accordingly, 1-butanol solutions gave smooth films independently of their water content. Dioxane and DMF, which are both miscible with water but possess higher boiling points, similarly led to smooth films, thereby reinforcing the hypothesis that the patterns are due to leftover water during film casting which causes glass molecules to aggregate due to limited solubility in this poor solvent.

To further demonstrate this hypothesis, a water-soluble analogue, Glim-Br ionic glass 4 was spin-coated using ethanol and DMF, having a lower and a higher boiling point than water, respectively (unfortunately, its solubility was too low in most of the other solvents to perform additional screening). As expected, smooth films were obtained from both solvents. As compound $\mathbf{4}$ is soluble in water, the evaporation sequence does not matter: the presence of water does not cause molecules to aggregate during deposition, and the resulting films are uniform. By extension, our interpretation means that surface patterns are formed only when the compound is insoluble in the least volatile solvent of the mixture. As a proof-of-concept, Glim-Br salt $\mathbf{4}$ was deposited from an ethanol/toluene 9:1 mixture. This system mimics the solvent/water systems through the presence of a minor component possessing a higher boiling point than the main solvent and in which the deposited compound is insoluble. In these conditions, patterned films were obtained, confirming that the behavior observed for compounds 1-3 is indeed watertriggered.

Atomic force microscopy was used to probe in greater detail the surface features of the films. As expected, smooth films showed very uniform surfaces, as shown in Figure 2a. In contrast, the surface of patterned films showed one of several morphologies: 1) grainy reliefs with domes typically ranging from $100 \mathrm{~nm}$ to $600 \mathrm{~nm}$ in height and from $500 \mathrm{~nm}$ to $1.5 \mu \mathrm{m}$ in width (Figure 2b, labelled Pd in Table 1), 2) plateau-type structures which are similar in height to the dome structures but with more irregular, elongated shapes (Figure 2c, Pi in Table 1), or 3) a porous surface with "breath figure patterns" 34 up to $200 \mathrm{~nm}$ deep and ranging from $500 \mathrm{~nm}$ to $10 \mu \mathrm{m}$ in width (Figure 2d, Pp in Table 1).
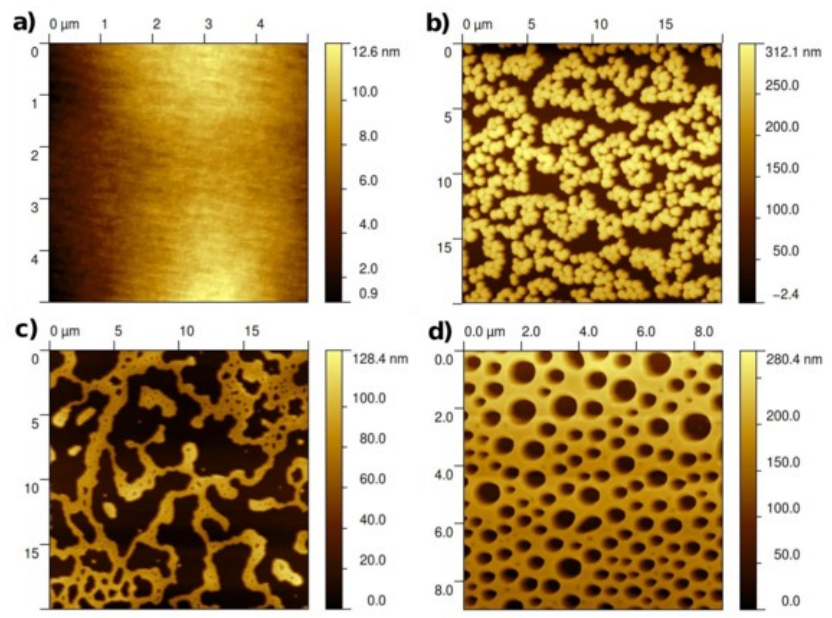

Fig. 2 AFM scans of films of mexylaminotriazine molecular glasses. a) Smooth film (compound $\mathbf{1}$ in dry ethyl ether), b) patterned film showing dome structures (compound $\mathbf{2}$ in ethanol), c) patterned film showing plateau-like structures (compound $\mathbf{3}$ in acetonitrile), d) patterned film showing pore structures (compound $\mathbf{3}$ in acetone).
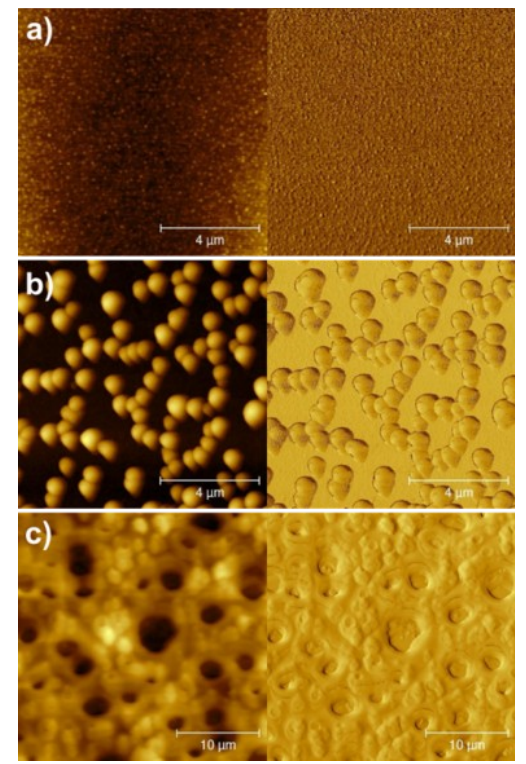

Fig. 3 Topography (left) and phase (right) AFM scans of: a) smooth film (compound $\mathbf{2}$ in toluene), b) patterned film showing dome structures (compound $\mathbf{2}$ in ethanol), c) patterned film showing pore structures (compound $\mathbf{1}$ in acetone).

In all cases, phase AFM scans (Figure 3) confirmed that the films were constituted of a single phase. The absence of birefringence upon observation of the films by optical 
microscopy under polarized light confirmed that the films are completely amorphous and that the surface features are not due to crystallization.

SEM further confirmed these observations. Figure 4 shows SEM images of films of compounds $\mathbf{1}$ and $\mathbf{3}$ spin-coated from acetone, yielding surface topologies containing domes and pores, respectively. While breath figure patterns are constituted of a continuous film littered with pores that can reach several hundred nanometers in diameter, dome patterns are constituted of individual particles scattered directly on the surface of the substrate, with sizes also ranging up to a few hundred nanometers. Images recorded at $45^{\circ}$ angle confirmed that the particles are isolated on the substrate (Figure S9).

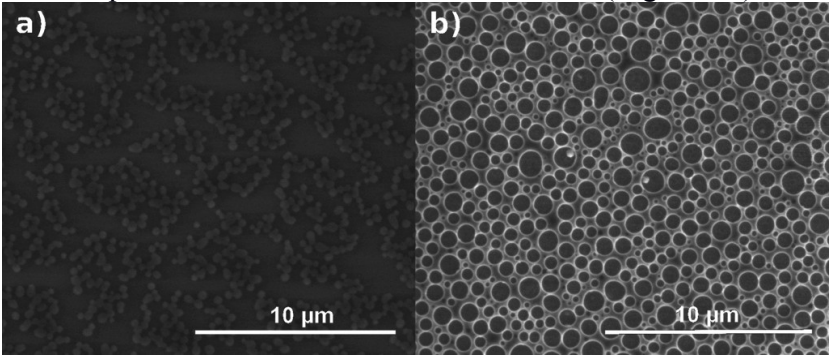

Fig. 4 Scanning electron microscopy images of films of compounds 1 and 3 spin-coated from acetone. a) Compound $\mathbf{1}$ showing dome patterns, b) compound $\mathbf{3}$ showing pore patterns.

As can be observed from Table 1, the surface morphology of patterned films is strongly correlated with the solvent used, and is fairly uniform between different compounds aside from a few exceptions. Solvents that are less hygroscopic, such as ethyl ether, ethyl acetate and THF, tend to favor breath figure patterns. Small pores were even observed scattered on the surface of films deposited from water-saturated dichloromethane, even though the films were optically transparent. On the other hand, acetone, acetonitrile and ethanol predominantly gave grainy morphologies with dome structures.

The effect of the substrate on surface morphology and pattern formation was evaluated by casting films of compounds 1-3 under representative conditions yielding both smooth (toluene and dry dichloromethane) and patterned (acetone and ethanol) films on glass slides rendered hydrophobic by silanization with phenyltrichlorosilane. Comparisons between hydrophilic and hydrophobic substrates are summarized in Table 2. In all cases, no notable changes were observed in surface patterning behavior depending on the polarity or chemical nature of the substrate (Figure S1). In the case of patterned films, the surface features observed were in almost all cases identical independently of the substrate. This reinforces the hypothesis that the behavior observed during film deposition is caused by the solvent evaporation sequence during spin-coating and not by the difference of surface energy at the film/substrate interface.

To monitor the effect of concentration of the solution on patterning behavior, compounds 1-3 were deposited from acetone at concentrations ranging from $0.02 \mathrm{M}$ to $1.0 \mathrm{M}$. It can be observed in Table 3 that patterned films occur until concentrations on the order of $0.5 \mathrm{M}$ are reached, at which point the water (or poor solvent) content relative to solute becomes too low for surface patterns to form. Interestingly, the concentration where smooth films started being generated varied upon the polarity of the aryl- or alkylamino group of the compound, with the minimal concentration giving a smooth film from acetone being $0.2 \mathrm{M}$ for hydroxy-substituted glass 3, 0.5 M for bis(mexyl) parent compound 1 , and $1.0 \mathrm{M}$ for bulkier adamantyl-substituted derivative 2. Arguably, this is due to the impact of molecular structure on aqueous solubility.

Figure 5 illustrates schematically the proposed formation mechanism for the various thin film morphologies encountered. On the left-most case (5a), the molecular glass is dissolved in a pure good solvent whose evaporation during spin-coating systematically leads to smooth films. This is observed in Table 1 for all dry solvents (it is reminded that THF, acetone, acetonitrile and ethanol were not dried prior to the experiments). When the glass is dissolved in a mixture of a good and a poor solvent $(5 b-d)$, the outcome depends on the relative volatility of the solvents. In the case where the poor solvent is the most volatile ( $5 b)$, no phase separation occurs during evaporation and smooth films are obtained, irrespective of the amount of poor solvent. An example of this scenario is the deposition of compound 1 from water-saturated 1-butanol. On the other hand, when the poor solvent is less volatile, its

Table 2 Comparison of surface morphology for films of compounds 1-3 cast from $0.02 \mathrm{M}$ solutions in various solvents onto untreated substrates (hydrophilic) or substrates silanized with phenyltrichlorosilane (hydrophobic).

$\begin{array}{ccccc}\text { Solvent } & \text { Surface } & \mathbf{1} & \mathbf{2} & \mathbf{3} \\ \text { Toluene } & \text { Hydrophilic } & \mathrm{S} & \mathrm{S} & - \\ & \text { Hydrophobic } & \mathrm{S} & \mathrm{S} & - \\ \text { Dichloromethane (dry) } & \text { Hydrophilic } & \mathrm{S} & \mathrm{S} & - \\ & \text { Hydrophobic } & \mathrm{S} & \mathrm{S} & - \\ \text { Acetone } & \text { Hydrophilic } & \mathrm{Pp} & \mathrm{Pd} & \mathrm{Pd} \\ & \text { Hydrophobic } & \mathrm{Pp} & \mathrm{Pd} & \mathrm{Pp} \\ \text { Ethanol } & \text { Hydrophilic } & \mathrm{Pd} & \mathrm{Pd} & \mathrm{Pd} \\ & \text { Hydrophobic } & \mathrm{Pd} & \mathrm{Pd} & \mathrm{Pd}\end{array}$

S: Smooth film; Pd: Patterned film with domes; Pp: Patterned film with pores.

Table 3 Comparison of surface morphology of films of compounds 1-3 cast from solution in various concentrations in acetone.

$\begin{array}{cccc}\text { Concentration (M) } & \mathbf{1} & \mathbf{2} & \mathbf{3} \\ 0.02 & \mathrm{Pp} & \mathrm{Pd} & \mathrm{Pd} \\ 0.05 & \mathrm{Pd} & \mathrm{Pd} & \mathrm{Pd} \\ 0.10 & \mathrm{Pd} & \mathrm{Pd} & \mathrm{Pd} \\ 0.20 & \mathrm{Pd} & \mathrm{Pd} & \mathrm{S} \\ 0.50 & \mathrm{~S} & \mathrm{Pd} & \mathrm{S} \\ 1.0 & \mathrm{~S} & \mathrm{~S} & -\end{array}$

S: Smooth film; Pd: Patterned film with domes; Pp: Patterned film with pores.

concentration gradually increases during the spin-coating process. This leads to a liquid-liquid phase separation to form a good solvent-rich phase (containing the vast majority of the glass molecules) and a poor solvent-rich phase, each phase being saturated in the other solvent. Depending on the details of the liquid-liquid phase diagram, the initial fraction of each solvent and their relative volatility, patterned films with 
domes or with pores (or an irregular structure containing both) can be obtained. Domes (5c) are expected when the poor solvent constitutes the continuous phase, such that isolated droplets of the good solvent containing the molecular glass are deposited on the substrate, ultimately yielding isolated precipitated particles scattered on the surface. This is observed, for example, for compound $\mathbf{1}$ when using saturated ethyl ether since water (the poor solvent) is initially present in a large amount and is much less volatile than ethyl ether. This scenario is also observed for the hydrophilic compound $\mathbf{4}$ when spin-coated from the 9:1 ethanol/toluene mixture, where toluene is the poor solvent. Finally, pores (5d) are observed when the phase separation leads to the formation of poor solvent droplets in a continuous matrix of the good solventrich phase. In such cases, the evaporation of the droplets leaves an imprint on the film surface that appears as the surface pores. This is observed, for instance, for compound 1 films prepared from water-saturated ethyl acetate since the poor solvent fraction is moderate.

\section{Thermal Annealing Behavior}

Films of bis(mexylamino) derivative $\mathbf{1}$ in both dry and saturated ethyl ether, along with films of Glim-Br 4 cast from ethanol, on both untreated and silanized glass substrates, were submitted to thermal annealing at approximately $\mathrm{Tg}+15^{\circ} \mathrm{C}$
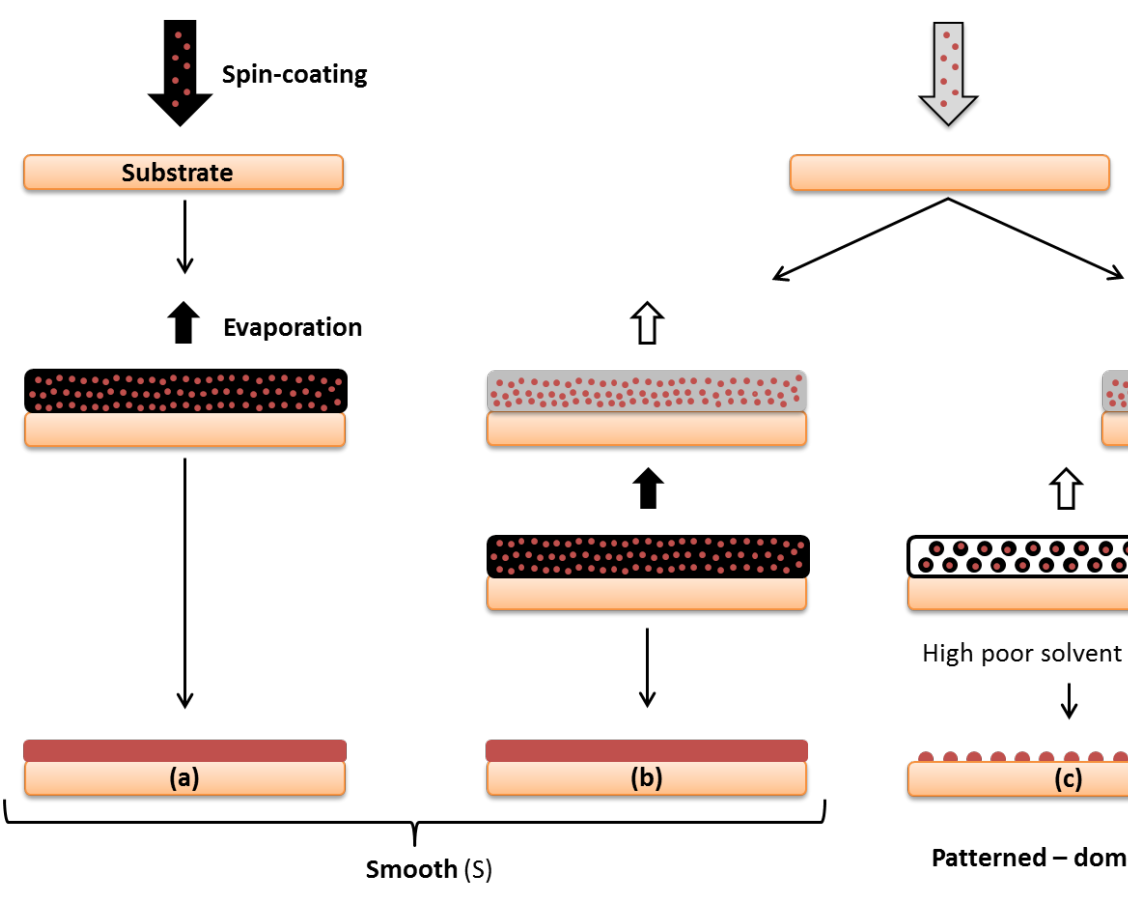

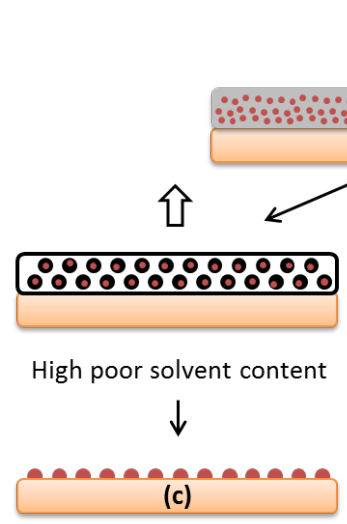

Patterned - domes (Pd)

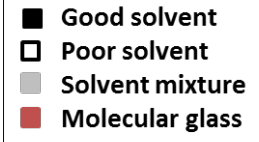

Molecular glass

Fig. 5 Schematic representation of the proposed model for spontaneous surface patterning occurring during film deposition by spin-coating for compounds 1-4. a) Formation of a smooth film from a pure solvent, b) formation of a smooth film from a good solvent / poor solvent mixture, c) formation of a patterned film with dome patterns, and d) formation of a patterned film with pore patterns.

(110 ${ }^{\circ} \mathrm{C}$ for compound $1,90{ }^{\circ} \mathrm{C}$ for compound 4) for $60 \mathrm{~min}$, and the films were observed by optical microscopy. Films of compound 1 deposited on hydrophilic untreated glass clearly started showing dewetting upon heating (Figure 6a-b), independently of initial surface morphology, though the film deposited from saturated ether, which was already patterned, showed the greatest extent of dewetting observed among any condition screened in this study. This behavior is attributable to unfavorable interactions between the high-energy, hydrophilic substrate and the ambipolar molecular glass molecules. On the other hand, films of highly polar Glim-Br salt 4 remained unchanged (Figure 6c). In sharp contrast, none of the films cast on hydrophobic silanized substrates showed any dewetting during annealing (Figure 6d-f). In the initially patterned film cast from saturated ether (Figure 6e) surface patterns even started to wet the substrate upon annealing.
Compound 4 gave highly uneven films, which is possibly a consequence of poor interactions with the hydrophobic surface. The observed thermal behavior was corroborated with both UV-visible spectroscopy and AFM after annealing (Figure S8). Whereas the favored film morphology during spin-coating is independent of the substrate because it is kinetically driven, thermal annealing allows the system to equilibrate to the most stable film morphology, which takes into account interactions between the molecules and the substrate.

\section{FT-IR Spectroscopy}

In an attempt to detect any differences in supramolecular aggregation between films with different surface morphologies, FT-IR spectroscopy was performed on films of compounds 1-4. For simplicity, ethyl acetate was selected as a 
representative solvent, because both smooth and patterned films can be accessed by varying the water content.
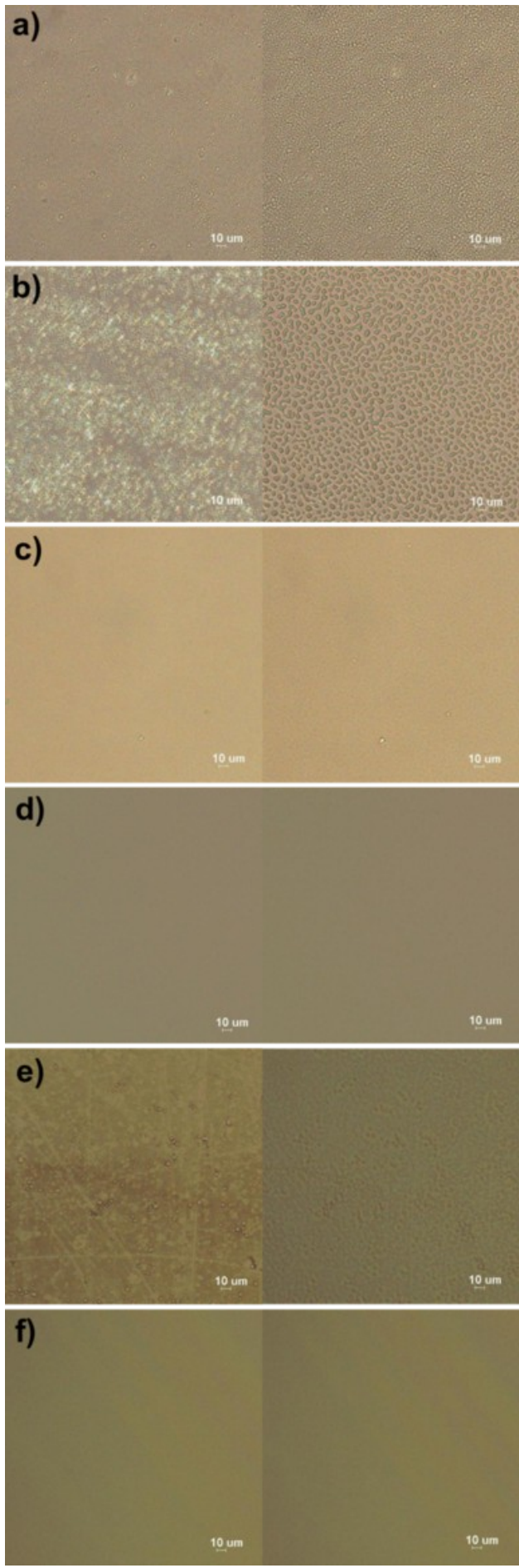

Fig. 6 Optical microscopy images of films of compounds 1 and 4 , before (left) and after (right) thermal annealing during $60 \mathrm{~min}$ at $110{ }^{\circ} \mathrm{C}$ for compound 1 or $90^{\circ} \mathrm{C}$ for compound 4 . Solvents used for deposition and surface treatments are indicated for each film. a) Compound 1, dry ethyl ether, untreated substrate; b) compound 1, saturated ethyl ether, untreated substrate; c) compound 4, ethanol, untreated substrate; d) compound $\mathbf{1}$, dry ethyl ether, silanized substrate; e) compound $\mathbf{1}$, saturated ethyl ether, silanized substrate; f) compound $\mathbf{4}$, ethanol, silanized substrate.
The ratio of hydrogen-bonded N-H groups vs. N-H groups not participating in hydrogen bonding has been previously shown to be correlated to the glass transition of the materials, and is indicative of the degree of aggregation within the material. Normalized bonded/free N-H ratios were thus calculated for compounds 1-3 and are reported in Table 4. No significant variation is observed in the degree of hydrogen bonding between smooth and patterned films for all compounds studied. Furthermore, no noticeable amounts of residual water or ethyl acetate were present in any of the films, therefore the composition of the films were identical for both smooth and patterned films. Moreover, $\mathrm{C}-\mathrm{H}, \mathrm{C}=\mathrm{C}$ and $\mathrm{C}=\mathrm{N}$ bands were essentially identical between smooth and patterned films for each compound. The organization at the molecular level thus seems identical regardless of the surface morphology. In a similar fashion, no major changes could be observed in the FT-IR spectra of samples 1-4 (Figures S10-S13) before and after thermal annealing, despite changes in morphology observed during heating. These results once more corroborate that the materials constituting those films are identical in spite of the various surface patterns observed.

\section{Conclusions}

Developing efficient, low-cost and rapid methods for tuning the thin film morphology is of significant interest in forming controlled organic nanostructures.

Table 4 Ratios between hydrogen-bonded and free N-H bands in FT-IR spectra of films of compounds 1-3 cast from dry or water-saturated ethyl acetate. The results were averaged over three spectra for each film.

Compound
1
2
3

Solvent
Ethyl acetate (dry)
Ethyl acetate (saturated)
Ethyl acetate (dry)
Ethyl acetate (saturated)
Ethyl acetate (dry)
Ethyl acetate (saturated)

Bonded/Free N-H Ratio

$2.70 \pm 0.07$

$2.7 \pm 0.2$

$1.85 \pm 0.03$

$1.71 \pm 0.04$

$1.01 \pm 0.01$

$1.02 \pm 0.03$

Mexylaminotriazine glasses were found to form films that exhibit surface patterns when cast from solvents containing residual water, in which the compounds are mostly insoluble. The surface features observed were demonstrated to be amorphous aggregates resulting from a liquid-liquid phase separation that occurs during the spin-coating. By studying systematically this phenomenon, we clearly identified specific process conditions under which different morphologies can be achieved. Our findings take advantage of an usually unwanted behavior by transforming it into a process for spontaneous surface patterning. This behavior shown by mexylaminotriazine glasses opens a new window towards the formation of thin films presenting desirable surface patterns because 1) it involves single-component systems composed of small molecules, 2) it is independent of the molecular structure of the glass (provided it is insoluble in water, or more generally, in the least volatile solvent of the mixture), 3) the films can be deposited from solution, during which surface patterning occurs spontaneously, 4) the surface morphology can be readily controlled from the choice of the solvent, 5) it 
is substrate-independent and 6) the films are amorphous independently of the surface morphology.

\section{Acknowledgements}

The authors acknowledge the funding from the Fonds de Recherche du Québec - Nature et Technologies (FRQNT \# 2012-PR-147034), the Natural Sciences and Engineering Research Council (NSERC \#327116 and \#312493), and the Academic Research Programme (ARP) of RMC. AL thanks NSERC for a Vanier graduate scholarship. The authors are also grateful to Prof. Christian Reber from Université de Montréal for providing access to the UV-Visible spectrometer and to Dr. René Gagnon (Université de Sherbrooke) for mass spectrometry analysis.

\section{Notes and references}

a Department of Chemistry, Queen's University, Kingston, ON, K7L 3N6, Canada. Fax: + 1 613-533-6669; Tel: +1 613-533-6749; E-mail: nunzijm@queensu.ca

b Département de Chimie, Université de Montréal, Montréal, H3C 3J7, Canada. Fax: +1 514-340-5290; Tel: +1 514-340-5762; E-mail: c.pellerin@umontreal.ca

c Department of Chemistry and Chemical Engineering, Royal Military College of Canada, Kingston, ON, K7K 7B4, Canada. Fax: +1 613-5429489; Tel: +1 613-541-6000x3694; E-mail: Olivier.lebel@rmc.ca $\dagger$ Electronic Supplementary Information (ESI) available: additional UVVisible spectra, FT-IR spectra of films, and AFM scans for all films. See DOI: $10.1039 / \mathrm{b} 000000 \mathrm{x} /$

$\$$ Marvin was used for drawing, displaying and characterizing chemical structures, substructures and reactions, Marvin 6.0.0, 2013, ChemAxon (http://www.chemaxon.com).

1 Handbook of Electronic and Photonic Materials, S. Kasap and P. Capper (Eds.), Springer (2006).

2 Handbook of Organic Materials for Optical and (Opto)Electronic Devices: Properties and Applications, O. Ostroverkhova, Woodhead Publishing Series in Electronic and Optical Materials (2013).

3 Intermolecular and Surface Forces, J.N. Israelachvili, Elsevier (2011)

4 S.R. Forrest, Nature 2004, 428, 911-918.

5 A. Sharma, Langmuir 1993, 9, 861-869.

6 Y. Xia, J.A. Rogers, K.E. Paul, G.M. Whitesides, Chem. Rev. 1999, 99, 1823-1848

7 R. Seemann, S. Herminghaus, K. Jacobs, J. Phys.: Condens. Matter 2001, 13, 4925-4938.

8 K.H. Lee, S.M. Kim, H. Jeong, G.Y. Jung, Soft Matter, 2012, 8, 465471
9 Thompson, C.V. Solid-state dewetting of thin films. Annu. Rev. Mater. Res. 2012, 42, 399-434.

10 A. Turak, J.Phot. Sci. Technol. 2013, 3, 1-10.

11 D. Gentili, G. Foschi, F. Valle, M. Cavallini, F. Biscarini, Chem. Soc. Rev. 2012, 41, 4430-4443.

12 P. Lee, W.-C. Li, B.-J. Chen, C.-W. Yang, C.-C. Chang, I. Botiz, G. Reiter, T.-L. Lin, J. Tang, A.C.-M. Yang, ACS Nano 2013, 7, 6658-6666. 13 J.Z. Wang, Z.H. Zheng, H.W. Li, W.T.S. Huck, H. Sirringshaus, Synth. Met. 2004, 146, 287-290.

14 A. Benor, A. Hoppe, V. Wagner, D. Knipp, Thin Solid Films 2007, $515,7679-7682$.

15 S. Carnazza, S. Satriano, S.J. Guglielmino, Phys.: Condens. Matter 2006, 18, S2221-S2230.

16 S. Yang, F. Xu, S. Ostendorp, G. Wilde, H. Zhao, Y. Lei, Adv. Funct. Mater. 2011, 21, 2446-2455.

17 S.A. Burke, J.M. Topple, P. Grutter, J. Phys. Cond. Matter 2009, 21, 423101

18 N. Maruyama, T. Koito, J. Nishida, T. Sawadaishi, X. Cieren, K. Ijiro, O. Karthaus, M. Shimomura, Thin Solid Films 1998, 327-329, 854856.

19 J. Heier, J. Groenewold, S. Huber, F. Nüesch, R. Hany, Langmuir 2008, 24, 7316-7322.

20 A. Tomioka, S. Kinoshita, A. Fujimoto, Mol. Cryst. Liq. Cryst. 2007, $471,69-80$

21 H. George, Q. Guo, Thin Solid Films 2009, 517, 2651-2655.

22 S. Kowarik, A. Gerlach, S. Sellner, L. Cavalcanti, F. Schreiber, $A d v$. Eng. Mater. 2009, 11, 291-294.

23 O. Karthaus, C. Adachi, S. Kurimura, T. Oyamada, Appl. Phys. Lett. 2004, 84, 4696-4698.

24 H. Yabu, Polym. J. 2013, 45, 261-268.

25 O. Lebel, T. Maris, M.-È. Perron, E. Demers, J.D. Wuest, J. Am. Chem. Soc. 2006, 128, 10372-10373.

26 A. Plante, D. Mauran, S.P. Carvalho, J.Y.S.D. Pagé, C. Pellerin, O. Lebel, J. Phys. Chem. B 2009, 113, 14884-14891.

27 A. Plante, S. Palato, O. Lebel, A. Soldera, J. Mater. Chem. C 2013, 1, 1037-1042.

28 J.D. Wuest, O. Lebel, Tetrahedron 2009, 65, 7393-7402.

29 R.N. Eren, A. Plante, A. Meunier, A. Laventure, Y. Huang, J.G. Briard, K.J. Creber, C. Pellerin, A. Soldera, O. Lebel, Tetrahedron 2012, 68, 10130-10144.

30 A. Laventure, A. Soldera, C. Pellerin, O. Lebel, New J. Chem. 2013, 37, 3881-3889.

31 Kirby, R.; Sabat, R.G.; Nunzi, J.-M.; O. Lebel, J. Mater. Chem. C

2014, 2, 841-847.

32 F. Brochard-Wyart, J.-M. di Meglio, D. Quéré, P.-G. de Gennes, Langmuir 1991, 7, 335-338

33 M. Ruths, N.A. Alcantar, J.N. Israelachvili, J. Phys. Chem. B 2003, 107, 11149-11157.

34 M.S. Park, J.K. Kim, Langmuir 2004, 20, 5347-5352. 